\section{MECHANISM OF ACTION OF ADJUVANT}

Polyadenylic-polyuridylic acid is a non-toxic double stranded complex of synthetic polyribonucleotides and a proved potent modulator of both humoral and cellular immune responses. The complex is also an inducer of interferon. Although results of direct determination of interferon in patients receiving the complex were negative, ${ }^{1}$ in later studies we found an enhancement of interferon mediated protein kinase p67 $\mathrm{K}$ in mouse plasma and $\mathrm{p} 72 \mathrm{~K}$ in human plasma in response to treatment with polyadenylic-polyuridylic acid. ${ }^{5}$ We have also reported that treatment of tumour bearing mice with the complex in association with cyclophosphamide results in a synergistic inhibition of tumour characterised by more retarded tumour growth, lower mortality, and a higher rate of tumour free survival than in mice treated with either agent alone. Furthermore, in these tumour bearing mice receiving such combined treatment there was a significant enhancement of natural killer (NK) cell activity. ${ }^{\circ}$ Recently we have studied in more detail the NK boosting effect of polyadenylic-polyuridylic acid in mice in parallel with an assay of an enzyme marker for the production and action of interferon-namely, 2.5 A synthetase. Enhanced NK cell activity accompanied increased activities of 2.5 A synthetase in mice treated with polyadenylic-polyuridylic acid. ${ }^{7}$ In patients an increase of $\mathrm{NK}$ cell activity as well as an increase of $2.5 \mathrm{~A}$ synthetase activity after one intravenous injection of $60 \mathrm{mg}$ polyadenylic-polyuridylic acid was also observed (A G Hovanessian et al, paper in preparation). In view of these observations we hypothesise that interferon and NK cell activity probably play a part in the overall mechanism of action of polyadenylic-polyuridylic acid as an adjunct to surgery in breast cancer.

Polyadenylic-polyuridylic acid appears to interact with many cell populations, ${ }^{8}$ so that its biological activity might therefore be exerted at different levels. Indeed, in patients 24 hours after a single intravenous injection of $30 \mathrm{mg}$ of the complex we observed that the mean percentage of $\mathrm{E}$ rosette forming cells was significantly $(\mathrm{p}<0.001)$ higher than that found before the injection $(60.8 \% \quad v 51.0 \%)$, confirming our observation on T lymphocytes in mice. ${ }^{9}$

The relevance of the biological effects to the therapeutic action so far observed remains to be determined.

This work was supported by the Cancer Research Institute (New York), CNRS, CNAMTS (Division ASS), and Institut GustaveRoussy.

\section{References}

${ }^{1}$ Lacour J, Lacour F, Spira A, et al. Adjuvant treatment with polyadenylicpolyuridylic acid (polyA-polyU) in operable breast cancer. Lancet $1980 ;$ ii :161-4.

${ }^{2}$ Peto R, Pike MC, Armitage P, et al. Design and analysis of randomised clinical trials requiring prolonged observations of each patient. II. Analysis and examples. Br $\mathcal{F}$ Cancer $1977 ; 35: 1-39$.

3 Bonadonna G, Valagussa P, Rossi A, et al. Multinodal therapy with CMF in resectable breast cancer with positive axillary nodes. The Milan Institute experience. In: Mathe G, Bonadonna G, Salmon S, eds. Adjuvant therapies of cancer. Recent results in cancer research. Berlin: Springer Verlag, 1982:149-56.

Rossi A, Bonadonna G, Valagussa P, et al. Multinodal treatment in operable breast cancer: five-year results of the CMF programme. Br Med f 1981 ;282:1427-31.

${ }^{5}$ Hovanessian AG, Riviere Y, Montagnier L, Michelson M, Lacour J, Lavour F. Enhancement of interferon-mediated protein kinase on mouse and human plasma in response to treatment with polyadenylicpolyuridylic acid (polyA-polyU). F IFN Res 1982;2:209-15.

${ }^{6}$ Youn JK, Lacour $\mathrm{F}$, Hue $\mathrm{G}$. Inhibition of $\mathrm{C} 3 \mathrm{H} / \mathrm{HE}$ mouse mammary tumour growth by combined treatment with cyclophosphamide and polyadenylic-polyuridylic acid. Cancer Res 1982;42:4706-11.

7 Youn JK, Hovanessian AG, Riviere Y, Hue G, Lacour F. Enhancement of natural killer cell activity and 2-5A synthetase in mice treated with polyadenylic-polyuridylic acid. Cell Immunol 1983;79:298-308.

${ }^{8}$ Johnson AG. Modulation of the immune system by synthetic polynucelotides. Springer Semin Immunopathol 1979;2:149-68.

${ }^{9}$ Donner M, Vaillier O, Lacour F. Changes in lymphocyte subpopulations in mice receiving a single injection of polyA-polyU. Ann Immunol Inst Pasteur 1977;128:1039-52.

(Accepted 8 December 1983)

\title{
Beneficial effect of fish oil on blood viscosity in peripheral vascular disease
}

\author{
B E WOODCOCK, E SMITH, W H LAMBERT, W MORRIS JONES, J H GALLOWAY, \\ $M$ GREAVES, F E PRESTON
}

\begin{abstract}
Reports suggest that the low incidence of ischaemic heart disease in Greenlandic Eskimos is related to the effect of a diet rich in eicosapentaenoic acid on platelet reactivity and plasma lipid concentrations. A double blind randomised investigation was therefore conducted of the effects on blood viscosity of dietary supplementation with an oil rich in this fatty acid (1.8 $\mathrm{g} / \mathrm{day}$, given as fish oil) and an eicosapentaenoic acid poor oil (as corn/olive oil)
\end{abstract}

University Department of Haematology and Department of Surgery Royal Hallamshire Hospital, Sheffield

B E WOODCOCK, MRCP, senior registrar

E SMITH, FIMLS, medical laboratory scientific officer

W H LAMBERT, FRCS, senior registrar

W MORRIS JONES, FRCS, consultant surgeon

J H GALLOWAY, BSC, research scientist

$M$ GREAVES, MD, senior lecturer and honorary consultant in haematology

F E PRESTON, MD, reader and consultant in haematology

Correspondence to: Dr F E Preston, University Department of Haematology, Royal Hallamshire Hospital, Sheffield S10 2JF. in patients with peripheral arterial disease. A statistically significant reduction in whole blood viscosity was observed at seven weeks in those patients receiving the eicosapentaenoic acid rich oil. No changes in plasma viscosity, haemoglobin concentration, packed cell volume, or platelet count were seen. A significant fall in plasma triglyceride concentration was also noted only in the patients receiving oil rich in eicosapentaenoic acid; plasma concentrations of cholesterol and high density lipoprotein cholesterol were unchanged.

It is concluded that rheological changes that result from a diet rich in eicosapentaenoic acid may contribute to the suggested protective effects of such a diet against arterial disease and that such changes are of potential therapeutic importance in established arterial disease.

\section{Introduction}

There is now good evidence that Greenlandic Eskimos have a low incidence of myocardial infarction, and there appears to be 
a strong possibility that this relates to their high dietary intake of the $w-3$ polyunsaturated fatty acid eicosapentaenoic acid. The finding of lower plasma cholesterol and triglyceride concentrations in Eskimos living in Greenland than in those living in Denmark provided a possible causal link between diet and the reduced incidence of myocardial infarction. ${ }^{1}$ Recently most investigators have addressed themselves to the relation between eicosapentaenoic acid and changes in platelet function and in platelet and vessel wall prostaglandin biosynthesis. ${ }^{2}$ Rheological abnormalities, however, are also considered to be important in occlusive vascular disease. We have therefore examined the effect of a fish oil rich in eicosapentaenoic acid on plasma and whole blood viscosity in patients with chronic peripheral vascular disease. We have also looked at its effect on plasma cholesterol and triglyceride concentrations and their lipoprotein subfractions.

\section{Patients and method}

The study was performed as a double blind randomised trial. Nineteen patients with intermittent claudication participated, of whom 15 were men and four women; their ages ranged from 56 to 75 years. Severity of disease was assessed before and after seven weeks of dietary supplementation. Clinical evaluation was performed by the same vascular surgeon on both occasions. In addition, the presence and site of disease were determined by Doppler ultrasound. The systolic pressures of the posterior tibial and dorsalis pedis pulses were compared with the brachial artery systolic pressure, the ratios (pressure indices) being used as a measure of disease severity. All patients were attending a vascular clinic and were ineligible for surgery, and all gave fully informed consent. No patient had diabetes mellitus or thrombocytosis.

The patients were randomised to receive either a fish oil rich in eicosapentaenoic acid (MaxEPA; Seven Seas Health Care Ltd, Marfleet) or an identical capsule containing a mixture of corn and olive oil. Five capsules were given twice daily for seven weeks. The fish oil treated patients received a daily intake of $1.8 \mathrm{~g}$ eicosapentaenoic acid. Table I lists the fatty acid composition of the oils. Compliance was confirmed by examination of the fatty acid composition of platelet membrane phospholipids ( $\mathrm{J}$ Galloway et al, unpublished observations).

All blood samples were taken after an overnight fast. These were obtained at the start of the study and after seven weeks of continuous administration of the oil. Whole blood viscosity was measured at $37^{\circ} \mathrm{C}$ using a Wells-Brookfield cone and plate microviscosimeter at two rates of shear, 230/s and 23/s. Since the packed cell volume represents the most important single factor influencing whole blood viscosity, both uncorrected and packed cell volume corrected whole blood viscosity are presented. In the latter the results are corrected to a constant packed cell volume of $0 \cdot 45(45 \%)$. Packed cell volume was measured by the microhaematocrit method. Plasma viscosity was measured at $25^{\circ} \mathrm{C}$ using a Coulter-Harkness capillary viscosimeter. Saline $(3.6 \%)$ was used as standard with a viscosity of $0.944 \mathrm{mPa} s$ $(0.944 \mathrm{cP})$. Control values were obtained from normal hospital staff and corrected to a packed cell volume of 0.45 .

Within five days of sampling the very low density lipoproteins were separated from the low and high density lipoproteins by ultracentrifugation ( $105000 \mathrm{~g}$ for 18 hours). A tube shearing technique was used to separate the very low density lipoproteins from the high density and low density lipoproteins. Separation was achieved by electrophoresis using agarose gels in $0.05 \mathrm{M}$ barbitone buffer. The lipoprotein fractions were analysed for cholesterol and triglyceride concentrations using a Technicon AAII autoanalyser.

Statistical analyses were by Student's $t$ tests.

\section{Results}

Seven men and three women took the capsules of fish oil (rich in eicosapentaenoic acid), and eight men and one woman received capsules of corn/olive oil. All patients were mobile and had had claudication distances ranging from 14 to $1600 \mathrm{~m}$ ( 15 yards to a mile) (median $183 \mathrm{~m} ; 200$ yards). The pressure index in the affected limb ranged from 0.34 to 0.78 . There was no difference between the groups in age or disease severity. In the fish oil supplemented group one patient was receiving metoprolol, hydralazine, and bendrofluazide for hypertension and one glyceryl trinitrate for angina. In the corn/olive oil group two patients had ischaemic heart disease, one treated with oxprenolol and the other nifedipine. Two patients were receiving bendrofluazide. During the study no alteration in prescribed drugs or smoking habit occurred.

Four patients felt improved after taking the capsules of fish oil; three noted an increase of $46 \mathrm{~m}$ in claudication distance, and one no longer had rest pain. Two patients in the corn/olive oil group felt improved;

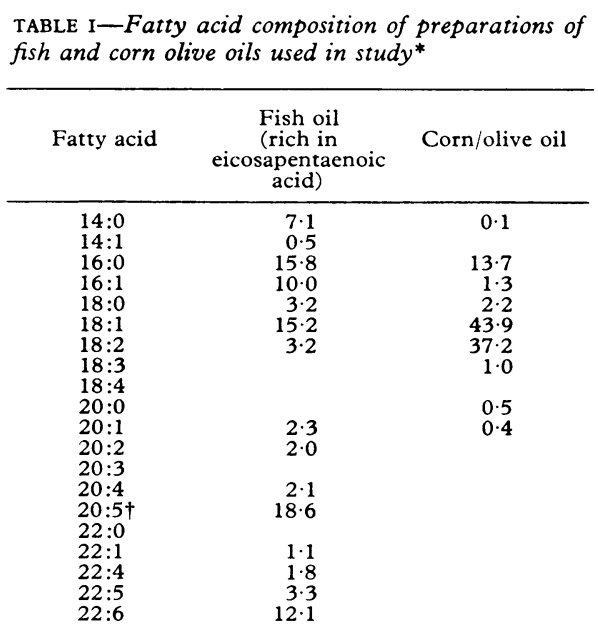

* Left hand column shows numerical abbreviations of carbon atoms and second number indicates number of double bonds present in molecule. Relative content of each fatty acid given in $\mathrm{mol} \%$ in middle column for fish oil and in right hand column for corn/olive oil. $\dagger$ Eicosapentaenoic acid.

TABLE II-Whole blood viscosity corrected and uncorrected for packed cell volume, and plasma viscosity in patients treated with either fish oil (rich in eicosapentaenoic acid) or corn/olive oil. Values are means (1 SD given in parentheses)

\begin{tabular}{|c|c|c|c|c|c|c|}
\hline \multirow[b]{3}{*}{$\begin{array}{l}\text { Patient } \\
\text { group }\end{array}$} & \multicolumn{4}{|c|}{ Whole blood viscosity ( $\mathrm{mPa}$ s) } & \multirow{3}{*}{$\begin{array}{l}\text { Packed } \\
\text { cell } \\
\text { volume }\end{array}$} & \multirow{3}{*}{$\begin{array}{c}\text { Plasma } \\
\text { viscosity } \\
(\mathrm{mPa} \mathrm{s})\end{array}$} \\
\hline & \multicolumn{2}{|c|}{ Uncorrected } & \multicolumn{2}{|c|}{ Corrected } & & \\
\hline & $230 / \mathrm{s}$ & $23 / \mathrm{s}$ & $230 / \mathrm{s}$ & $23 / \mathrm{s}$ & & \\
\hline $\begin{array}{l}\text { Before } \\
\text { After }\end{array}$ & $\begin{array}{l}5.90(1.06) \\
4.99(0.92) \dagger\end{array}$ & $\begin{array}{l}9.73(1.83) \\
8.31(1.46)^{*}\end{array}$ & $\begin{array}{c}\text { Fish oil } \\
5.61(0.73) \\
4.80(0.58) \dagger \\
\text { Cornlolive oi }\end{array}$ & $\begin{array}{l}9.13(1.38) \\
+\quad 7.88(0.85)^{*} \\
i l\end{array}$ & $\begin{array}{l}48 \cdot 4(5 \cdot 7) \\
47 \cdot 5(6 \cdot 2)\end{array}$ & $\begin{array}{l}1.75(0.09) \\
1.71(0.08)\end{array}$ \\
\hline $\begin{array}{l}\text { Before } \\
\text { After }\end{array}$ & $\begin{array}{l}5.45(0.51) \\
5.30(0.76)\end{array}$ & $\begin{array}{l}8.94(1.07) \\
8.43(1.32)\end{array}$ & $\begin{array}{l}5.38(0.37) \\
5.20(0.63)\end{array}$ & $\begin{array}{l}8.82(0.78) \\
8.22(1.12)\end{array}$ & $\begin{array}{l}46 \cdot 0(3 \cdot 0) \\
45 \cdot 5(2 \cdot 8)\end{array}$ & $\begin{array}{l}1.75(0.14) \\
1.68(0.12)\end{array}$ \\
\hline
\end{tabular}

${ }^{*} \mathrm{p}<0.05 ;+\mathrm{p}<0.01$

Conversion: SI to traditional units-Viscosity: $1 \mathrm{mPa} \mathrm{s}=1 \mathrm{cP}$.

one had an increase of $73 \mathrm{~m}$ in claudication distance, and one no longer had rest pain. In one patient from each group a previously absent pulse was present after supplementation. In no patient was the disease found to be altered on Doppler ultrasound, and in neither group did the pressure indices change with supplementation.

Before treatment the mean laboratory values showed no significant difference between the two groups. After seven weeks of treatment there were no significant alterations in haemoglobin concentration, packed cell volume, mean cell volume, or platelet count in either group.

Before the study the mean values for corrected whole blood viscosity at both rates of shear $(230 / \mathrm{s}$ and $23 / \mathrm{s})$ for the entire group were significantly raised $(p<0.01)$ compared with those in the normal controls (normal values (mean and $1 \mathrm{SD} ; \mathrm{n}=45): 4 \cdot 49(0 \cdot 2) \mathrm{mPa} s$ at $230 / \mathrm{s} ; 7.56(0.14) \mathrm{mPa}$ at $23 / \mathrm{s}$ ) (table II). There were no significant differences between the treatment groups or between either group and the entire study group of patients. In both groups the mean plasma viscosity was also raised compared with normal (normal value (mean and $1 S D ; n=45): 1.61(0.06) \mathrm{mPa}$ ) (table II).

At seven weeks of treatment statistically significant reductions in whole blood viscosity were obtained at both rates of shear in samples from patients receiving the fish oil supplement (table II); no difference was detectable when samples from patients receiving corn/olive oil 
were compared with their pretreatment control values. There were no significant changes in the plasma viscosity of either group.

The mean plasma triglyceride concentration for both groups was above the normal range, and the plasma triglyceride concentration fell significantly after supplementation with fish oil but not with corn/olive oil-from a mean (1 SD) of $2.01(0.98)$ to $1.46(0.79) \mathrm{mmol} / 1$ [178 (87) to $129(70) \mathrm{mg} / 100 \mathrm{ml}$ in the fish oil supplemented group and from $1.78(0.50)$ to $1.81(0.78) \mathrm{mmol} / 1[158(44)$ to $160(69) \mathrm{mg} / 100 \mathrm{ml}]$ in the corn/olive oil group. Most of the reduction occurred in the very low density lipoprotein triglyceride, a fall in high density lipoprotein also contributing. Neither of these latter changes was statistically significant. We detected no statistically significant change in the total plasma cholesterol value or high density lipoprotein subfraction.

\section{Discussion}

The mortality from coronary artery disease in Greenlandic Eskimos is extremely low. This is believed to be due to environmental factors, particularly diet. ${ }^{1}$ Most recent studies of this phenomenon have focused attention on the effects of eicosapentaenoic acid-an important constituent of whale, seal, and oily fish-on platelet biochemistry. Factors relating to the development of atherosclerosis are highly complex, however, and abnormalities other than those relating to platelets have been described in patients with this disorder. These include raised plasma fibrinogen values and increased whole blood viscosity. ${ }^{3}$ Kobayashi et al reported that the mean whole blood viscosity was significantly lower in a fishing community than in a farming community. By supplementing the diet of normal volunteers with eicosapentaenoic acid they were able to produce a similar fall in whole blood viscosity and suggested that the acid might be of value for this purpose. ${ }^{4}$ Thus we have looked at the effect of dietary supplementation with oil rich in eicosapentaenoic acid on whole blood and plasma viscosity in patients with peripheral vascular disease.

The mean whole blood viscosity and plasma viscosity were significantly raised before administration of oil in both groups of patients. These abnormalities have been reported in association with peripheral vascular disease ${ }^{3}$ and have been shown to have prognostic significance. ${ }^{5}$

Our study shows that a reduction in whole blood viscosity occurs in patients with peripheral vascular disease when they receive dietary supplementation of $1.8 \mathrm{~g}$ eicosapentaenoic acid a day given as fish oil. The mechanism of this reduction is not precisely known. As there was no reduction in either packed cell volume or plasma viscosity it seems likely that it is due, at least in part, to changes in the red cell membrane. Terano et al studied normal volunteers receiving dietary supplementation with eicosapentaenoic acid and demonstrated incorporation of the acid into red cell membrane phospholipids and found an increase in red cell deformability which positively correlated with membrane eicosapentaenoic acid content. ${ }^{6}$ Although the effect of other oil constituents cannot be excluded, these and our results suggest that it is the eicosapentaenoic acid in the fish oil which is responsible for reducing whole blood viscosity.

The reduction in plasma triglyceride concentration after supplementation with fish oil is well recognised. It has been shown in normal volunteers ${ }^{7}$ and in patients with ischaemic heart disease. ${ }^{8}$ Our finding of a significant reduction in plasma triglyceride concentration is consistent with these. In contrast with these studies, we failed to detect any alteration in total cholesterol concentration or in the cholesterol content of the lipoprotein fractions. The amount of fish oil used may have been too small to produce these effects, as they do appear to be dose dependent. ${ }^{\text {? }}$

No conclusions with regard to clinical efficacy can be drawn from our study since it was not designed to assess this. Nevertheless, the beneficial effect of fish oil on whole blood viscosity in patients with peripheral vascular disease suggests a potential therapeutic role in such patients, as there is evidence that rheological factors are important in determining clinical events. ${ }^{910}$ Recent studies suggest that platelet vessel wall interactions are influenced by certain physicochemical properties of red cells ${ }^{11}$ and that platelet activation may influence red cell deformability. ${ }^{12}$ Thus the actions of eicosapentaenoic acid on platelets and red cells may not be mutually exclusive. The potential role of eicosapentaenoic acid in reducing whole blood viscosity by mechanisms independent of packed cell volume and plasma viscosity is worthy of further study.

This work was supported by research grants from the British Heart Foundation and the special trustees for the Former United Sheffield Hospitals. We acknowledge Janice Mitcheson and John G McGirk, of Sterling Winthrop Research and Development, Alnwick, Northumberland, for lipoprotein analyses, and the department of medical physics, Royal Hallamshire Hospital, for performing the Doppler ultrasound measurements.

\section{References}

${ }^{1}$ Bang HO, Dyerberg J, Nielsen AB. Plasma lipid and lipoprotein pattern in Greenlandic west-coast Eskimos. Lancet 1971 ;i:1143-5.

2 Dyerberg J, Bang HO, Stofferson E, Moncada S, Vane JR. Eicosapentaenoic acid and prevention of thrombosis and atherosclerosis ? Lancet 1978;ii:117-9.

${ }^{3}$ Dormandy JA, Hoare E, Colley J, Arrowsmith DE, Dormandy TL. Clinical, haemodynamic, rheological, and biochemical findings in 126 patients with intermittent claudication. $\mathrm{Br}$ Med $\mathrm{F}$ 1973;iv:576-81.

${ }^{4}$ Kobayashi S, Hirai A, Terano T, Hamazaki T, Tamura Y, Kumagai A. Reduction in blood viscosity by eicosapentaenoic acid. Lancet 1981 ;ii: 197.

${ }^{5}$ Dormandy JA, Hoare E, Khattab AH, Arrowsmith DE, Dormandy TL. Prognostic significance of rheological and biochemical findings in patients with intermittent claudication. Br Med F 1973;iv:581-3.

${ }^{6}$ Terano T, Hirai A, Hamazaki T, et al. Effect of oral administration of highly purified eicosapentaenoic acid on platelet function, blood viscosity, red cell deformability in healthy human subjects. Atherosclerosis $1983 ; 46: 321-31$.

${ }^{7}$ Sanders TAB, Roshanai F. The influence of different types of W-3 polyunsaturated fatty acids on blood lipids and platelet function in healthy volunteers. Clin Sci 1983;64:91-9.

${ }^{8}$ Saynor R, Verel D. Eskimos and their diets. Lancet 1983;i:1335.

9 Bailey MJ, Yates CJP, Johnston CLW, Somerville PG, Dormandy JA. Preoperative haemoglobin as a predictor of outcome of diabetic amputations. Lancet 1979; ii:168-70.

${ }^{10}$ Bouhoutsos J, Morris T, Chavatzas D, Martin P. The influence of haemoglobin and platelet levels on the results of arterial surgery. Br $\mathcal{F}$ Surg 1974;51:984-6.

${ }^{11}$ Aarts PA, Bolhuis PA, Kjell S, Sakariassen KS, Heethaar RM, Sixma JJ. Red blood cell size is important for adherence of blood platelets to artery subendothelium. Blood $1983 ; 62: 214-7$.

12. Palinski W, Torsellini A, Doni L. Influence of platelet activation on erythrocyte deformability. Thromb Haemost 1983;49:84-6.

(Accepted 22 December 1983)

ONE HUNDRED YEARS AGO If we may take literally a statement published in the New York Medical Record, the "Heathen Chinee" must be a most satisfactory patient, for he invariably carries out instructions to the letter, is very grateful, and always pays his bills. The infant "Chinee" is a very small baby as a rule, and does not average more than six pounds. In the arrangements for childbed, it would appear that they have a full appreciation of the importance of cleanliness; as napkins for the lochia, they use a thick soft paper which looks like muslin, and they also use paper for protecting the bedding, one sheet being replaced by another as soon as it has become soiled. The paper is a stout, smooth, light brown fabric, not much like ordinary Western papers, and is prepared for use by crumpling and rubbing it with the hand. Being tough and thick, it is completely transformed by this process, and makes a soft fabric, almost impermeable to water, and admirably fitted for temporary protection to the bedding. This practice seems to have the great advantage of economy and cleanliness, inasmuch as the napkins and bed-protector for each case are absolutely new, and therefore quite free from any possible taint of infection. It might be worth while for the benevolent persons who lend to poor lying-in women a "bag" of linen to take into consideration the possibility of using this cheap and cleanly substitute. (British Medical fournal 1884 ; i :235.) 